\title{
Children conceived by in vitro fertilisation after fresh embryo transfer
}

\author{
S W D’Souza, E Rivlin, J Cadman, B Richards, P Buck, B A Lieberman
}

\begin{abstract}
Aims-To compare the outcome in in vitro fertilisation (IVF) children (after fresh embryo transfer) from multiple and singleton births with one another, and with normally conceived control children.

Methods-A cohort of 278 children (150 singletons, 100 twins, 24 triplets and four quadruplets), conceived by IVF after three fresh embryos had been transferred, born between October 1984 and December 1991 , and 278 normally conceived control children (all singletons), were followed up for four years after birth. They were assessed for neonatal conditions, minor congenital anomalies, major congenital malformations, cerebral palsy and other disabilities. Control children, all born at term, were matched for age, sex and social class.
\end{abstract}

Results-The ratio of male:female births was 1.03. Forty six per cent of IVF children were from multiple births; $34.9 \%$ were from preterm deliveries; and $43.2 \%$ weighed less than $2500 \mathrm{~g}$ at birth. The IVF singletons were on average born one week earlier than the controls, weighed $400 \mathrm{~g}$ less, and had a threefold greater chance of being born by caesarean section. The higher percentage of preterm deliveries was largely due to multiple births and they contributed to neonatal conditions in $45.0 \%$ of all IVF children. The types of congenital abnormalities varied: $3.6 \%$ of IVF children and $2.5 \%$ of controls had minor congenital anomalies, and $2.5 \%$ of IVF children and none of the controls had major congenital malformations. The numbers of each specific type of congenital abnormality were small and were not significantly related to multiple births. IVF children $(2.1 \%)$ and $0.4 \%$ of the controls had mild/moderate disabilities. They were all from multiple births, including two children with cerebral palsy who were triplets.

Conclusions-The outcome of IVF treatment leading to multiple births is less satisfactory than that in singletons because of neonatal conditions associated with preterm delivery and disabilities in later childhood. A reduction of multiple pregnancies by limiting the transfer of em- bryos to two instead of three remains a high priority.

(Arch Dis Child 1997;76:F70-F74)

Keywords: IVF; multiple births; congenital abnormalities; disabilities.

Multiple births are probably more common now than they used to be $\mathrm{e}^{1-4}$ and treatment of infertility by ovarian stimulation, gamete intrafallopian transfer (GIFT), or in vitro fertilisation (IVF) is considered to be an important contributor to this increase. ${ }^{25-7}$ The increase has raised concerns not only for social reasons but also because twins and triplets are more likely to have a higher perinatal mortality than singletons. ${ }^{8-10}$ Considerable attention has been given to the incidence of major congenital malformations in children conceived by IVF: in some women embryos have been implanted after cleavage, while in others the embryos have been frozen before use. The incidence of major congenital malformations in both has been reported to be similar to that in population based estimates. $^{91112}$ Data from the register of IVF and GIFT pregnancies in Australia and New Zealand suggest, however, a higher incidence of transposition of the great vessels and spina bifida in newborn infants conceived by IVF than in the general population. ${ }^{13}$ Moreover, a survey of all children born after assisted conception, including IVF, has shown an increased incidence of congenital malformations. ${ }^{14}$

In general, prospective follow up studies comparing IVF pregnancies with appropriate controls, rather than with population based norms, have not found an association with congenital malformation, ${ }^{15}$ or with impaired growth and development. ${ }^{15} 16$ Recently, we reported such a study on children grown from cryopreserved embryos ${ }^{17} 18$ The incidence of major congenital malformations and minor congenital anomalies was not significantly different from that in normally conceived controls who were siblings, cousins, or peers of the study group. There were no children with cerebral palsy but some children had squints and conductive hearing loss, and one child had Down's syndrome.

We have also followed up children conceived by IVF after fresh embryo transfer since 1984. 


\begin{tabular}{|c|c|c|c|c|c|c|c|c|}
\hline & \multicolumn{6}{|l|}{$I V F$} & \multirow{2}{*}{\multicolumn{2}{|c|}{ Controls $(n=278)$}} \\
\hline & \multicolumn{2}{|c|}{ Singleton $(n=150)$} & \multicolumn{4}{|c|}{ Multiple births $(n=128)$ Total $(n=278)$} & & \\
\hline \multicolumn{9}{|l|}{ Gestational age (weeks) } \\
\hline Mean (SD) & $38.41 \ddagger$ & $(2.51)$ & 35.24 & $(3.06)$ & 36.95 & (3.19) & $39.45 \neq \ddagger$ & $(1.25)$ \\
\hline$\geq 37$ & 127 & $(84.7 \%)$ & 54 & $(42.2 \%)$ & 181 & $(67.3 \%)$ & 278 & $(100 \%)$ \\
\hline $32-36$ & 19 & $(12.7 \%)$ & 57 & $(44.5 \%)$ & 76 & $(27.3 \%)$ & 0 & $(0.0 \%)$ \\
\hline$<32$ & 4 & $(2.7 \%)$ & 17 & $(13.3 \%)$ & 21 & $(7.6 \%)$ & 0 & $(0.0 \%)$ \\
\hline \multicolumn{9}{|l|}{ Birth weight ( $g$ ) } \\
\hline Mean (SD) & $3016.3 \ddagger$ & $(641.6)$ & 2078.6 & $(612.7)$ & 2584.5 & $(783.2)$ & $3379.8 \ddagger$ & $(428.3)$ \\
\hline$<2500$ & 22 & $(14.7 \%)$ & 98 & $(76.6 \%)$ & 120 & $(43.2 \%)$ & 2 & $(0.7 \%)$ \\
\hline$<1500$ & 5 & $(3.3 \%)$ & 25 & $(19.5 \%)$ & 30 & $(10.8 \%)$ & 0 & $(0.0 \%)$ \\
\hline$<1000$ & 1 & $(0.7 \%)$ & 2 & $(1.6 \%)$ & 3 & $(1.1 \%)$ & 0 & $(0.0 \%)$ \\
\hline \multicolumn{9}{|l|}{ Mode of delivery } \\
\hline Vaginal & $110 \ddagger$ & $(73.3 \%)$ & 57 & $(44.5 \%)$ & 167 & $(60.1 \%)$ & 259 㧊 & $(93.2 \%)$ \\
\hline Caesarean section & 40 & $(26.7 \%)$ & 71 & $(55.5 \%)$ & 111 & $(39.9 \%)$ & 19 & $(6.8 \%)$ \\
\hline Boys & 80 & $(53.3 \%)$ & 61 & $(47.7 \%)$ & 141 & $(50.7 \%)$ & 141 & $(50.7 \%)$ \\
\hline Girls & 70 & $(46.7 \%)$ & 67 & $(52.3 \%)$ & 137 & $(49.3 \%)$ & 137 & $(49.3 \%)$ \\
\hline Sex ratio $(M: F)$ & 1.14 & & 0.91 & & 1.03 & & 1.03 & \\
\hline \multicolumn{9}{|l|}{ Social class } \\
\hline 1 & 0 & $(0.0 \%)$ & 3 & $(2.3 \%)$ & 3 & $(1.1 \%)$ & 3 & $(1.1 \%)$ \\
\hline 2 & 8 & $(5.3 \%)$ & 10 & $(7.8 \%)$ & 18 & $(6.5 \%)$ & 18 & $(6.5 \%)$ \\
\hline 3 & 118 & $(78.7 \%)$ & 94 & $(73.4 \%)$ & 212 & $(76.3 \%)$ & 212 & $(76.3 \%)$ \\
\hline 4 & 24 & $(16.0 \%)$ & 24 & $(16.4 \%)$ & 45 & $(16.2 \%)$ & 45 & $(16.2 \%)$ \\
\hline
\end{tabular}

Levels of significance: IVF singleton $v s$ multiple births.

$\ddagger \mathrm{P}<0.001$.

Total IVF vs controls

$\ddagger \ddagger \mathrm{P}<0.01$.

In preliminary studies we reported our findings on the types of congenital abnormalities, postnatal growth, and development in these children. ${ }^{19}{ }^{20}$ We have now extended this study in duration and number because we felt that IVF children from multiple births may have a less favourable outcome. There is a particular difficulty in the case of multiple births in obtaining controls matched for maternal age, parity, multiplicity of pregnancy, history of infertility, mode of delivery and preterm birth.

\section{Methods}

We prospectively followed up children conceived after the transfer of three fresh embryos in the IVF Unit at St Mary's Hospital, Manchester. The cohort consisted of a total of 278 children who were consecutive births between October 1984 and December 1991. During this period, the 11 neonates who died were excluded from the study. Details of the IVF procedure used at our hospital have been reported elsewhere. ${ }^{21}$ The control group consisted of 278 normally conceived children born at term. One control child was chosen of the same sex and social class as the IVF child. Both groups of children were born at a hospital near their place of residence. Their social class was determined by the father's occupation. ${ }^{22}$

The children were seen for assessments for four years after birth. The assessments included a history, general medical examination to identify any congenital abnormality, neurological abnormality, or disability and developmental assessment. ${ }^{24}$ The history included information about relatives who were known to have congenital abnormalities, maternal medication and illness during pregnancy, and occupation. The general medical examination included a detailed physical assessment for minor congenital and major congenital structural abnormalities, neurological abnormality, and disability. Major congenital abnormalities were taken to be those conditions which we considered could cause impor- tant social or functional impairment and the remaining abnormalities were considered to be minor. ${ }^{25}$ Developmental delay $(\mathrm{DQ}<70)$ was assessed according to Griffiths scores, as suggested by Cooke. ${ }^{27}$ We had access to the case notes to collect relevant information about birth characteristics, congenital abnormalities, neurological abnormalities and other disabilities. Preterm infants were born before 37 completed weeks of gestation, as measured from the first day of mother's last menstrual period.

Numbers of children in the IVF group and controls were compared using the $\chi^{2}$ test. Mean values were compared using Student's $t$ test.

\section{Results}

In the IVF group 128 (46\%) children were from multiple births, $78 \%(n=100)$ of these were twins, $18 \%(n=24)$ triplets, and 3\% $(n=4)$ higher order births. The overall ratio of boys to girls was 1.03 with no significant variation in the ratio by multiplicity of birth (table 1). Thirty five per cent of IVF children were born preterm. For IVF singletons, $15.3 \%$ were preterm compared with $57.8 \%$ from multiple births. The mean gestational age was thus lower in IVF children from multiple births than in singletons and in the IVF group overall than in controls (table 1). In the IVF group $43.2 \%$ of children weighed less than $2500 \mathrm{~g}, 10.8 \%$ less than $1500 \mathrm{~g}$, and $1.1 \%$ less than $1000 \mathrm{~g}$, compared with $0.7 \%$ of control children who weighed less than $2500 \mathrm{~g}$. There were no children in the control group who weighed under $1500 \mathrm{~g}$ or less than $1000 \mathrm{~g}$. When singleton and multiple births were considered separately in the IVF group, the mean birthweight was significantly lower in children from multiple births (table 1). Of the deliveries, $39.9 \%$ in the IVF group, overall, were delivered by caesarean section compared with $6.8 \%$ of the controls. Within the IVF group caesarean section deliveries were higher in multiple births (55.5\%) than in singletons $(26.7 \%)$. Multiplicity of 
Table 2 IVF singletons and controls

\begin{tabular}{|c|c|c|}
\hline & \multicolumn{2}{|l|}{$I V F$} \\
\hline & Singletons $(n=150)$ & Controls $(n=150)$ \\
\hline \multicolumn{3}{|l|}{ Gestational age (weeks) } \\
\hline Mean (SD) & $38.41(2.52)^{\star \star}$ & $39.50(1.29)$ \\
\hline \multicolumn{3}{|l|}{ Birth weight (g) } \\
\hline Mean (SD) & $3016.3(641.6) \dagger$ & $3400.3(461.5)$ \\
\hline \multicolumn{3}{|l|}{ Mode of delivery } \\
\hline Vaginal & $110^{\star}$ & 136 \\
\hline Caesarean section & 40 & 14 \\
\hline
\end{tabular}

Paired data:

Levels of significance ${ }^{\star} \mathrm{P}<0.0001$.

${ }^{\star \star} \mathrm{P}<0.00001$

$+\mathrm{P}<0.000001$

Table 3 Neonatal conditions

\begin{tabular}{|c|c|c|c|c|}
\hline & \multicolumn{3}{|l|}{$I V F$} & \multirow[b]{2}{*}{$\begin{array}{l}\text { Controls } \\
(n=278)\end{array}$} \\
\hline & $\begin{array}{l}\text { Singleton } \\
(n=15)\end{array}$ & $\begin{array}{l}\text { Multiple births } \\
(n=128)\end{array}$ & $\begin{array}{l}\text { Total } \\
(n=278)\end{array}$ & \\
\hline Sepsis & 3 & 12 & 15 & 0 \\
\hline Conjunctivitis & 4 & 4 & 8 & 2 \\
\hline Hypoglycaemia & 1 & 1 & 2 & 0 \\
\hline Jittery & 1 & 1 & 2 & 0 \\
\hline Bruising & 1 & 0 & 1 & 1 \\
\hline Oral thrush & 1 & 1 & 2 & 0 \\
\hline Pneumonia & 0 & 3 & 3 & 0 \\
\hline Pneumothorax & 1 & 0 & 1 & 0 \\
\hline Meconium aspiration & 0 & 0 & 0 & 1 \\
\hline Respiratory distress & $11^{\star \star}$ & 42 & 53 & $1 \dagger$ \\
\hline \multicolumn{5}{|l|}{ Hypothermia (rectal } \\
\hline temperature $<35^{\circ} \mathrm{C}$ ) & 0 & 1 & 1 & 0 \\
\hline Apnoea & 1 & 0 & 1 & 0 \\
\hline Subependymal haemorrhage & 0 & 1 & 1 & 0 \\
\hline Intraventricular haemorrhage & 1 & 1 & 2 & 0 \\
\hline Bronchopulmonary dysplasia & 0 & 3 & 3 & 0 \\
\hline Urticarial rash & 0 & 0 & 0 & 1 \\
\hline Cephalhaematoma & 1 & 1 & 2 & 0 \\
\hline Jaundice (hyperbilirubinaemia) & $23^{\star \star}$ & 81 & 104 & $13 \dagger$ \\
\hline Feeding difficulty & 3 & 7 & 10 & 3 \\
\hline Patent ductus arteriosus & 3 & 6 & 9 & 0 \\
\hline Inguinal hernia & 2 & 3 & 5 & 0 \\
\hline Any of above & $\begin{array}{l}37^{\star \star} \\
(24.7 \%)\end{array}$ & $\begin{array}{l}88 \\
(68.8 \%)\end{array}$ & $\begin{array}{l}125 \\
(45 \%)\end{array}$ & $\begin{array}{l}21 \\
(7.6 \%)+\end{array}$ \\
\hline None & $\begin{array}{l}113 \\
(75.3 \%)\end{array}$ & $\begin{array}{l}40 \\
(31.3 \%)\end{array}$ & $\begin{array}{l}153 \\
(55 \%)\end{array}$ & $\begin{array}{l}257 \\
(92.4 \%)\end{array}$ \\
\hline
\end{tabular}

Levels of significance: IVF singleton $v s$ multiple births.

$\star \star \mathrm{P}<0.001$.

Total IVF $v s$ controls.

$+\mathrm{P}<0.001$.

Table 4 Minor congenital anomalies and major congenital malformations

\begin{tabular}{|c|c|c|c|c|}
\hline & \multicolumn{3}{|l|}{$I V F$} & \multirow[b]{2}{*}{$\begin{array}{l}\text { Controls } \\
(n=278)\end{array}$} \\
\hline & $\begin{array}{l}\text { Singleton } \\
(n=150)\end{array}$ & $\begin{array}{l}\text { Multiple births } \\
(n=128)\end{array}$ & $\begin{array}{l}\text { Total } \\
(n=278)\end{array}$ & \\
\hline \multicolumn{5}{|l|}{ Minor congenital anomalies: } \\
\hline Undescended testes & 3 & 2 & 5 & 0 \\
\hline Duplex kidney & 0 & 0 & 0 & 1 \\
\hline Talipes equinovarus & 0 & 0 & 0 & 2 \\
\hline Pigmented naevus & 1 & 0 & 1 & 1 \\
\hline Umbilical hernia & 1 & 1 & 2 & 0 \\
\hline Pelviectasis & 0 & 1 & 1 & 1 \\
\hline Pre-auricular skin tag & 0 & 0 & 0 & 1 \\
\hline Single palmar crease & 0 & 0 & 0 & 1 \\
\hline Subependymal cysts & 0 & 1 & 1 & 0 \\
\hline \multicolumn{5}{|l|}{ Major congenital malformations: } \\
\hline Microphthalmia, right eye & 0 & 1 & 1 & 0 \\
\hline Ventriculo-septal defect & 1 & 0 & 1 & 0 \\
\hline Gastroschisis & 1 & 0 & 1 & 0 \\
\hline Hydronephrosis & 1 & 0 & 1 & 0 \\
\hline Fused digits & 1 & 0 & 1 & 0 \\
\hline Dislocated hip & 1 & 1 & 2 & 0 \\
\hline Pyloric stenosis & 1 & 0 & 1 & 0 \\
\hline With minor congenital anomalies & $5(3.3 \%)$ & $5(3.9 \%)$ & $10(3.6 \%)$ & $7(2.5 \%)$ \\
\hline With major congenital malformations & $5(3.3 \%)$ & $2(1.6 \%)$ & $7(2.5 \%)$ & $0(0.0 \%)$ \\
\hline
\end{tabular}

births was not related to the social class distribution of the fathers (table 1).

As the IVF children were matched with controls for sex and social class (table 1) in further analysis it was only necessary to compare the IVF singletons against their matched controls for the unmatched variables: gestational age, birthweight, and mode of delivery. Table 2 shows that there was a highly significant difference in gestational age between the two cohorts; the IVF singletons were born on average one week earlier. There was also a highly significant difference in birthweights, the IVF singletons being on average $400 \mathrm{~g}$ lighter. Finally, there were more IVF singletons born by caesarean section than controls $(26 \%$ vs $9 \%)$.

Overall, in the IVF group $45 \%$ had neonatal problems compared with only $7.6 \%$ among the controls. IVF infants from multiple births had a higher proportion of neonatal problems compared with singletons (table 3), but the types of conditions were similar whether the infants were singletons or from multiple births. The most common disorders were sepsis, respiratory distress, jaundice and feeding difficulties.

Table 4 shows that the types of minor congenital anomalies and major congenital malformations varied in the IVF children, from singleton and multiple births, and in controls. Small numbers of children had each type of congenital abnormality. There were no significant differences in the prevalence of these conditions in IVF children from singleton and multiple births and, overall, between IVF children and controls. These congenital abnormalities were not obviously associated with a family history of a similar condition, or to maternal medication, illness during pregnancy, or occupation.

DEVELOPMENTAL OUTCOME

There were two IVF children from multiple births who had cerebral palsy. One child had a hemiplegia; she was one of triplets born at 32 weeks of gestational age, weighing $1778 \mathrm{~g}$ at birth, and with Apgar scores of 9 at 1 minute and 10 at 5 minutes of age. In the neonatal period she had respiratory distress and jaundice. The other child had cerebral diplegia; she was one of triplets who weighed $1440 \mathrm{~g}$ at birth at a gestational age of 30 weeks, with Apgar scores of 7 at 1 minute and 10 at 5 minutes of age. Her neonatal conditions included respiratory distress, jaundice, patent ductus arteriosus and inguinal hernia. The remaining developmental conditions included conductive hearing loss as a result of secretory otitis media, impaired vision attributable to microphthalmia, squint, and hearing difficulty (table 5). All six children with a disability were from IVF multiple births, none of the singletons was affected. The one control child with a disability had conductive hearing loss. The disabilities were considered to be mild or moderate in the IVF group and mild in the control group. ${ }^{27}$

\section{Discussion}

The outcome of IVF treatment leading to multiple births was less satisfactory than in singletons as the proportion of caesarean section deliveries, preterm births, low birthweight infants and neonatal conditions is higher the greater the number of fetuses. The neonatal 
Table 5 Developmental outcome

\begin{tabular}{lllll}
\hline & \multicolumn{2}{l}{ IVF } & & \\
\cline { 2 - 4 } & $\begin{array}{l}\text { Singleton } \\
(n=150)\end{array}$ & $\begin{array}{l}\text { Multiple births } \\
(n=128)\end{array}$ & $\begin{array}{l}\text { Total } \\
(n=278)\end{array}$ & $\begin{array}{l}\text { Controls } \\
(n=278)\end{array}$ \\
\hline Cerebral palsy & 0 & $2(1.6 \%)$ & $2(0.7 \%)$ & 0 \\
Conductive hearing loss & 0 & $1(0.8 \%)$ & $1(0.4 \%)$ & $1(0.4 \%)$ \\
Impaired vision & 0 & $1(0.8 \%)$ & $1(0.4 \%)$ & 0 \\
Squint & 0 & $1(0.8 \%)$ & $1(0.4 \%)$ & 0 \\
Learning difficulty & 0 & $1(0.8 \%)$ & $1(0.4 \%)$ & 0 \\
Developmental delay $(\mathrm{DQ}<70)$ & 0 & $2(1.6 \%)$ & $2(0.7 \%)$ & 0 \\
Type of disability: & 0 & 4 & 4 & 1 \\
$\quad$ Mild & 0 & 2 & 2 & 0 \\
$\quad$ Moderate & 0 & 0 & 0 & 0 \\
\hline Severe & & & & \\
\hline
\end{tabular}

conditions after fresh embryo transfer were similar to those reported in IVF infants from cryopreserved embryos. ${ }^{17}$ These conditions were associated with prematurity and some of them required neonatal intensive care. An increase in the incidence of multiple births would, therefore, have an impact on the use of neonatal services and would raise the cost of the service. Apart from this, our study has shown that multiple births may have an adverse effect on subsequent developmental outcome.

Although most children conceived by IVF after fresh embryo transfer seemed to survive as normal children, $2.1 \%$ had a mild or moderate disability, and the incidence of cerebral palsy was $0.7 \%$. The incidence of cerebral palsy in the general population (in Western Australia) suggests that the risks of producing a child with cerebral palsy in singleton, twin, and triplet pregnancies is $0.2 \%, 1.3 \%$, and $7.6 \%$, respectively. ${ }^{4}$ Another source of population based information is a survey in the United Kingdom that was limited to multiple births in which three or more infants survived the neonatal period, leading to a prevalence of cerebral palsy of 17.4 per 1000 triplet or higher order births. ${ }^{128}$ In our study there were 28 IVF children from triplet and higher order births, and two of these developed cerebral palsy, giving a prevalence of 71 per 1000 children which is higher than that expected from United Kingdom population based estimates, but similar to that from Western Australia.

The tendency to have more preterm deliveries and low birthweight infants in multiple births may increase the subsequent risk of cerebral palsy. ${ }^{49}$ There may be additional adverse effects of multiple births which occur at term because population based estimates have shown that in twins weighing $2500 \mathrm{~g}$ or more the risk of cerebral palsy is higher than in singletons of a similar birthweight. ${ }^{4}$ From the information available in our IVF children with cerebral palsy it is impossible to say whether they had prenatal brain damage or whether the brain damage was the result of neonatal conditions related to preterm delivery. Modern neonatal intensive care leads to the survival of such infants who manifest cerebral palsy in later childhood.

In multiple pregnancies, when one of twins or triplets dies in utero, there is a greater risk that the surviving fetus will develop cerebral palsy. ${ }^{429}$ It has been suggested that the insult which caused death in one fetus may lead to prenatal brain damage in the surviving fetus, increasing the risk of cerebral palsy to $10 \%$ in twins and $29 \%$ in triplets. ${ }^{4}$ This may have implications for the control of multiple births in assisted conception, as procedures have been suggested as being responsible for the deaths of some fetuses in early pregnancy. ${ }^{3031}$ In our study cerebral palsy that had occurred in triplets was not associated with fetal death in utero.

All the remaining disabilities at follow up in our IVF children were from multiple births. These included squints and conductive hearing loss, which have been described before in low birthweight children ${ }^{32}$ and in IVF children conceived from cryopreserved embryos. ${ }^{17}$ None of our children had developmental delay. We have already reported that the mean (SD) DQ was 116.9 (12.6) in IVF singletons and 106.9 (10.9) in children from multiple births at a mean (SD) chronological age of 25.5 (7.9) and 24.8 (5.1) months, respectively. ${ }^{20}$ The psychological development of children and mother-child relationships have been studied in IVF infants. ${ }^{33}$ Some feeding difficulties and sleep disorders were reported at 9 months of age and some signs of depression in the mothers. All these symptoms were reported to have resolved shortly afterwards. The development of IVF children was deemed to be satisfactory and relationships with their mothers excellent.

Several studies have considered possible reasons for congenital malformations after assisted conception and have discussed associations with the relatively advanced age of infertile couples, the underlying causes of infertility, the drugs used to induce ovulation or for luteal phase support, abnormal spermatozoa and the IVF procedures themselves. ${ }^{13} 3435$ In our study the incidence of congenital abnormalities was not increased in children from multiple births. Overall, the incidence of major congenital malformations that we found in the IVF group $(2.5 \%)$ is similar to that $(2.9 \%)$ reported in the MRC study ${ }^{9}$ and these figures are consistent with population based estimates for the United Kingdom. ${ }^{36}$ Microphthalmia and gastroschisis are two congenital malformations which were noted in our study but not in the MRC study ${ }^{9}$ or in prospective follow up studies after assisted conception. ${ }^{10151837}$ Chromosomal abnormalities have been reported before in IVF children, including Down's syndrome, Edward's syndrome and the Klinefelter syndrome, ${ }^{10}$ but were not seen in our study.

Minor congenital anomalies have received less attention in previous reports ${ }^{15}$ on the outcome of IVF pregnancies. Morin et a ${ }^{15}$ drew attention to two minor congenital anomalies, a Darwinian point and a high arched palate, whose incidence was higher than in normally conceived controls. These conditions were not seen in our IVF children. We found that haemangiomas were not common in IVF children from fresh embryos. We especially looked for haemangiomas because of their prevalence in children from cryopreserved embryos. ${ }^{18}$

Having shown the effects of multiple births, the question that now needs to be addressed is whether the transferred embryos should be 
further limited to a maximum of two to bring about a reduction in multiple pregnancies. A possible disadvantage of doing this would be a lowering of pregnancy rate in couples who are not typical of all parents as they tend to be older than average and their infertility may have resulted from medical or genetic disorders. ${ }^{12}$ Recent research into conditions which influence pregnancy rate including embryo "quality" and maternal age has shown that it is possible to transfer two embryos without lowering the chances of a successful pregnancy after IVF treatment. ${ }^{38}$ It may help to control the rising rate of multiple births to transfer two embryos only. This would reduce the incidence of neonatal conditions and the possibility of subsequent disability including cerebral palsy, reduce the uptake of neonatal services, and benefit such parents who are known to experience greater social and family difficulties in raising triplet and quadruplet children. ${ }^{28}$

We thank Mrs Jean French and Mrs Elaine Evans for secretarial assistance. We are grateful to Professor R D H Boyd for helpfu comments.

1 Botting BJ, MacDonald Davies I, Macfarlane AJ. Recent trends in the incidence of multiple births and associated mortality. Arch Dis Child 1987;62:941-50.

2 Dunn A, Macfarlane A. Recent trends in the incidence of multiple births and associated mortality in England and multiple births and associated mortality

3 Kiely JL, Kleinman JC, Kiely $M$. Triplets and higher-order multiple births: time trends and infant mortality. $A m \mathcal{F} D i$ multiple births: time trend
Child 1992;146:862-8.

4 Petterson B, Nelson KB, Watson L, Stanley F. Twins, triplets and cerebral palsy births in Western Australia in triplets and cerebral palsy births in

5 Webb S, Moore D, Stanley F. Increasing prevalence of multiple confinements in Western Australia and the impact of

6 Levene MI, Wild J, Steer P. Higher multiple births and the modern management of infertility in Britain. $\mathrm{Br} \mathcal{F}$ Obstet Gynaecol 1992;99:607-13.

7 Craft I, Ah-Moye M, Al-Shawaf T, Fiamanya W, Lewis P, Robertson D, et al. Analysis of 1071 GIFT procedures the case for a flexible approach to treatment. Lancet 1988;i:1094-8.

8 Australian In-Vitro Fertilization Collaborative Group. Invitro fertilization pregnancies in Australia and New Zealand, 1979-85. Med f Aust 1988;148:429-36.

9 MRC Working Party on Children Conceived by In Vitro Fertilization. Births in Great Britain resulting from assisted conception 1978-87. BMF 1990;300:1229-33.

10 Rizk B, Doyle P, Tan SL, Rainsbury P, Betts J, Brinsden P, Edwards RG. Perinatal outcome and congenital malformations in in-vitro fertilization babies from the BournHallam group. Hum Reprod 1991;6:1259-64.

11 Australian In-Vitro Fertilization Collaborative Group. High incidence of preterm births and early losses in pregnancy after in vitro fertilization. $B M \mathcal{F} 1985 ; 291: 1160-3$.

12 Tan SL, Doyle P, Campbell S, Beral V, Rizk B, Brinsden P, et al. Obstetric outcome of in vitro fertilization pregnancies compared with normally conceived pregnancies. $A m \mathcal{F}$ Obstet Gynecol 1992;167:778-84.
13 Lancaster PAL. Congenital malformations after in vitro fertilization. Lancet $1987 ; \mathbf{i i}: 1392-3$.

14 Cohen J, Mayaux MJ, Guihard-Moscato L. Pregnancy outcomes after in vitro fertilization. A collaborative study on 2342 pregnancies. Ann NY Acad Sci 1988;541:1-6.

15 Morin NC, Wirth FH, Johnson DH, Frank LM, Presburg HJ, Van de Water VL, et al. Congenital malformations and psychosocial development in children conceived by in vitro fertilization. F Pediatr 1989;115:222-7.

16 Brandes JM, Scher A, Itzkovites J, Thaler J, Sarid M, Gersoni-Baruch R. Growth and development of children
conceived by in vitro fertilization. Pediatrics 1992;90:424-9.

17 Sutcliffe AG, D'Souza SW, Cadman J, Richards B, McKinlay IA, Lieberman BA. Outcome in children from cryoprelay IA, Lieberman BA. Outcome in children from

18 Sutcliffe AG, D'Souza SW, Cadman J, Richards B, McKinlay IA, Lieberman B. Minor congenital anomalies, major congenital malformations and development in children conceived from

19 D'Souza SW, Rivlin E, Buck P, Lieberman BA. Altered sex ratios. Lancet 1989;i:689-90.

20 D'Souza SW, Rivlin E, Buck P, Lieberman BA. Children conceived by in vitro fertilization. In Mason PL, Lieberman BA, eds. Clinical IVF forum: current views in assisted reproduction. Manchester: Manchester University Press, 1990:70-8.

21 Troup SA, Matson RL, Critchlow JD, Morrall DR, Lieberman BA, Burslem RW. Cryopreservation of human embryos at the pronucleate, early cleavage or expanded embryos at the pronucleate, early cleavage or expanded 1990;38:133-9.

22 Office of Population, Censuses and Surveys. Classifications of Occupations. London: The Stationery Office, 1970

23 Griffiths R. Abilities of babies: A study in mental measurement. London: University Press, 1954.

24 Griffiths R. Abilities of babies: A study in mental measurement. Norfolk: Lowe and Boydone, 1976.

25 Smith DW. Classification, nomenclature and naming of morphologic defects. F Pediatr 1975;87:162-4

26 Holmes LB. Congenital malformations. $N$ Engl $f$ Med 1976;295:204-7.

27 Cooke RWI. Factors affecting survival and outcome at 3 years in extremely preterm infants. Arch Dis Child years in extrem

28 Botting JB, MacFarlane AJ, Price FV. Three, four and more. A study of triplet and higher order births. London: The Stationery Office, 1990.

29 Nelson KB, Ellenberg JH. Childhood neurological disorders in twins. Pediatr Perinat Epidemiol 1995;9:135-45.

30 Berkowitz RL, Lynch L, Chitkara U, Wilkins IA, Mehalek $\mathrm{KE}$, Alvarez E. Selective reduction of multiple pregnancies in the first trimester. N Engl f Med 1988;318:1043-7.

31 Howie PE. Selective reduction in multiple pregnancy. BMF 1988;297:433-4.

32 Marlow N, D'Souza SW, Chiswick ML. Neurodevelomental outcome in babies weighing less than $2001 \mathrm{~g}$ at birth. BMf 1987;294:1582-6.

33 Raoul-Duval A, Bertrand-Servais M, Letur-Könirsch H, Frydman R. Psycholgical follow-up of children born after in-vitro fertilization. Hum Reprod 1994;9:1097-2101.

34 Schlesselmann JJ. How does one assess the risk of abnormalities from human in-vitro fertilization. $A m \mathcal{F}$ Obstet Gynecol 1979;135:135-48.

35 Biggers JD. In-vitro fertilization and embryo transfer in human beings. N Engl f Med 1981;304:336-42.

36 Office of Population Censuses and Surveys (1982-8). Congenital malformation statistics. 1979 to 1985. London: HMSO (OPCS Series MB3).

37 Andrews MJ, Muasher SJ, Levy DL, Jones HW, Garcia JE, Rosenwaks Z, et al. An analysis of the obstetric outcome of
125 consecutive pregnancies conceived in vitro and 125 consecutive pregnancies conceived in vitro and resulting in 100

38 Staessen C, Janssenswillen C, Van E, Abbeel D, Devroey P. Avoidance of triplet pregnancies by elective transfer of two good quality embryos. Hum Reprod 1993;8:1650-3. 